Journal of Patient-Centered

4-19-2021

\title{
Seroprevalence of SARS-CoV-2 Antibody in Echocardiography and Stress Laboratory
}

\author{
Renuka Jain \\ Stacie Kroboth \\ Denise Ignatowski \\ Bijoy K. Khandheria
}

Follow this and additional works at: https://aah.org/jpcrr

Part of the Cardiology Commons, Cardiovascular Diseases Commons, Community Health and Preventive Medicine Commons, Diagnosis Commons, Epidemiology Commons, Infectious Disease Commons, Other Analytical, Diagnostic and Therapeutic Techniques and Equipment Commons, and the Patient Safety Commons

\section{Recommended Citation}

Jain R, Kroboth S, Ignatowski D, Khandheria BK. Seroprevalence of SARS-CoV-2 antibody in echocardiography and stress laboratory. J Patient Cent Res Rev. 2021;8:146-50. doi: 10.17294/ 2330-0698.1815

Published quarterly by Midwest-based health system Advocate Aurora Health and indexed in PubMed Central, the Journal of Patient-Centered Research and Reviews (JPCRR) is an open access, peer-reviewed medical journal focused on disseminating scholarly works devoted to improving patient-centered care practices, health outcomes, and the patient experience. 


\title{
Seroprevalence of SARS-CoV-2 Antibody in Echocardiography and Stress Laboratory
}

\author{
Renuka Jain, MD, ${ }^{1}$ Stacie Kroboth, BS, ${ }^{2}$ Denise Ignatowski, RDCS, ${ }^{1}$ Bijoy K. Khandheria, MD ${ }^{1}$ \\ ${ }^{1}$ Aurora Cardiovascular and Thoracic Services, Aurora Sinai/Aurora St. Luke's Medical Centers; University of \\ Wisconsin School of Medicine and Public Health, Milwaukee, WI; ${ }^{2}$ Advocate Aurora Research Institute, Advocate \\ Aurora Health, Milwaukee, WI
}

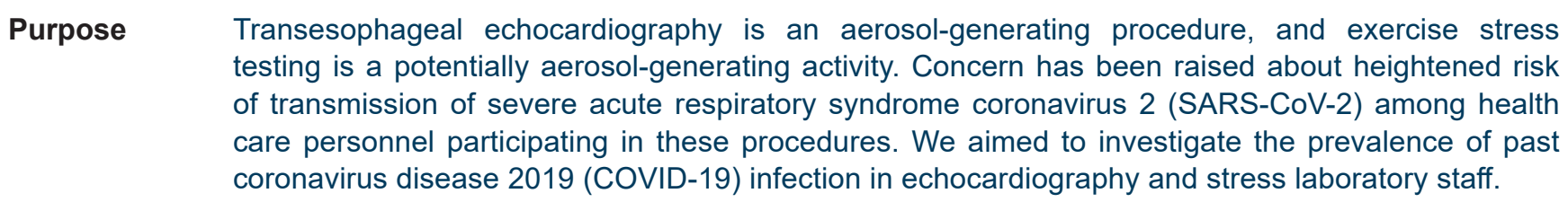

Methods All staff who worked in the echocardiography and stress laboratories of one high-traffic urban hospital from March 15, 2020, to June 15, 2020, were asked to voluntarily participate. Those willing to participate were consented, and past COVID-19 infection was confirmed by a SARS-CoV-2 IgG antibody test (ARCHITECT, Abbott Laboratories) from June 15, 2020, to July 3, 2020. Clinical data were collected from the electronic medical record, and self-reported symptoms were documented with a participant survey.

Results $\quad$ A total of 43 staff members (86.0\% of 50 total laboratory staff) participated. A majority of participants were less than 40 years old $(69.8 \%)$, were White $(86.0 \%)$, and were women $(79.1 \%)$; mean body mass index was $24.9 \pm 4.7 \mathrm{~kg} / \mathrm{m}^{2}$. Of the 43 staff members tested for past COVID-19 infection, 3 $(7.0 \%)$ had a positive SARS-CoV-2 IgG antibody result. There were no unique features in the 3 SARS-CoV-2 antibody-positive subjects; of these, 2 had known prior COVID-19 infection and 1 was asymptomatic.

Conclusions This study provides clinical data on the seroprevalence of SARS-CoV-2 antibody in echocardiography and stress laboratory staff who regularly participate in a variety of procedures that are or may be aerosol-generating. (J Patient Cent Res Rev. 2021;8:146-150.)

Keywords COVID-19; antibody; echocardiography; stress testing; SARS-CoV-2; seroprevalence

$\mathrm{E}$ merging in December 2019 in Wuhan, China, coronavirus disease 2019 (COVID-19) encompasses myriad clinical presentations. Recent literature has shown that COVID-19, which is caused by severe acute respiratory syndrome coronavirus 2 (SARS-CoV-2), can present with acute cardiac involvement. ${ }^{1,2}$ Echocardiography is a tool for evaluation of cardiovascular complications of COVID-19. The COVID-19 pandemic has raised unique challenges for echocardiography and cardiac stress laboratories due to the virus's transmission mode, primarily through human-to-human contact or respiratory droplets. ${ }^{3,4}$

Corresponding author: Renuka Jain, MD,

Aurora St. Luke's Medical Center, 2801 W. KK River Parkway, \#880, Milwaukee, WI 53215 (wi.publishing159@aah.org)
Transthoracic echocardiography (TTE), a still or moving image of the heart using ultrasound, is the most common type of echocardiogram and requires a sustained period of close physical contact during image acquisition. ${ }^{5}$ Transesophageal echocardiography (TEE) is an aerosolgenerating procedure. Exercise stress testing measures the heart's ability to respond to external stress and, whether paired with imaging or as a standalone test, is a potentially aerosol-generating procedure. ${ }^{6}$ As such, concern has been raised about a heightened risk of transmission among health care personnel participating in these procedures. ${ }^{7}$ Yet, echocardiography and stress laboratories are critical to a functioning hospital, providing vital services that identify cardiac emergencies, risk-stratify patients preparing for organ transplants, differentiate chest pain syndromes, and provide guidance for structural heart interventions. ${ }^{8,9}$

The echocardiography and stress laboratories at our hospital function as one clinical unit and are physically 
connected to each other, with staff in various clinical roles moving between areas throughout the day, multiple times a day. As this unit reopened fully in the beginning of June 2020, we sought to evaluate the extent to which our staff had been potentially exposed to COVID-19 during the 3-month time period from the initial declaration of a statewide public health emergency to full health system reopening. This exploratory study examined the seroprevalence of COVID-19 antibodies in the echocardiography and stress laboratory staff, recognizing that antibodies to SARS-CoV-2 proteins represent past COVID-19 infection.

\section{METHODS}

All full-time staff members who were employed exclusively by and physically present at the stress and echocardiography laboratories of a single urban, community-based hospital (Aurora St. Luke's Medical Center, Milwaukee, WI) from March 15, 2020, through June 15,2020 , were asked to voluntarily participate in immunoglobulin $\mathrm{G}$ ( $\mathrm{IgG}$ ) antibody testing for SARSCoV-2. Staff members who were on a leave of absence or who worked remotely during this time period were excluded. This study was approved by the health system's institutional review board, and informed consent was obtained for those willing to participate.

We collected blood samples of $\operatorname{IgG}$ antibody for SARS-CoV-2, an indicator of recent or prior infection. Laboratory values were collected from June 15, 2020, through July 3, 2020. The ARCHITECT SARS-CoV-2 IgG antibody test (Abbott Laboratories) was performed in-house using ARCHITECT instruments. The antibody for the test is directed to the nuclear capsid protein of the SARS-CoV-2 virus. Results were reported as an index, with values of $>1.4$ being positive. The sensitivity of the test is dependent on days of exposure ( $>14$ days postexposure: $98.7 \%$; 8-13 days postexposure: $92.0 \%$; 3-7 days postexposure: $50.0 \%$ ), and the test has a specificity of $99.2 \% .^{10}$

All staff members had been previously seen by the health system as patients, allowing clinical and demographic variables to be collected from the participating staff member's electronic medical record (Epic Systems Corporation). All participants underwent a brief survey to assess symptoms suggestive of prior COVID-19 infection. Categorical variables were summarized as count and proportion. Continuous variables were summarized as mean \pm standard deviation. Analyses were performed using Stata ${ }^{\circledR} 15$ software (StataCorp LLC).

Throughout the initial months of the COVID-19 pandemic, the echocardiography and stress labs remained open for urgent outpatient and full inpatient service. We continued to perform all echocardiography and stress services, implementing a variety of social distancing and public health interventions to keep our staff and patients safe (Figure 1). Temperature checks and symptom screening were adopted early (March 22, 2020), followed by universal masking and social distancing a week later. These behavioral interventions were mandated for all staff, visitors, and patients entering any part of the hospital campus. Midway through this 3-month time period, routine COVID-19 testing (48-72 hours preprocedure, with self-quarantine until procedure) of patients scheduled for TEE was enacted. The guidelines for personal protective equipment (PPE) outlined by the American Society of Echocardiography were followed closely, ${ }^{11}$ although it is noteworthy that recommendations are varied as to the appropriate PPE for exercise stress testing and TEE in patients in the COVID-19 era. ${ }^{11,12}$ Recommendations for preprocedure COVID-19 testing in asymptomatic patients is recommended universally for TEE, as are continued droplet precautions even with a negative COVID-19 test. ${ }^{11,13}$ Our policy called for staff use of PPE (N95 mask and face shield) when performing

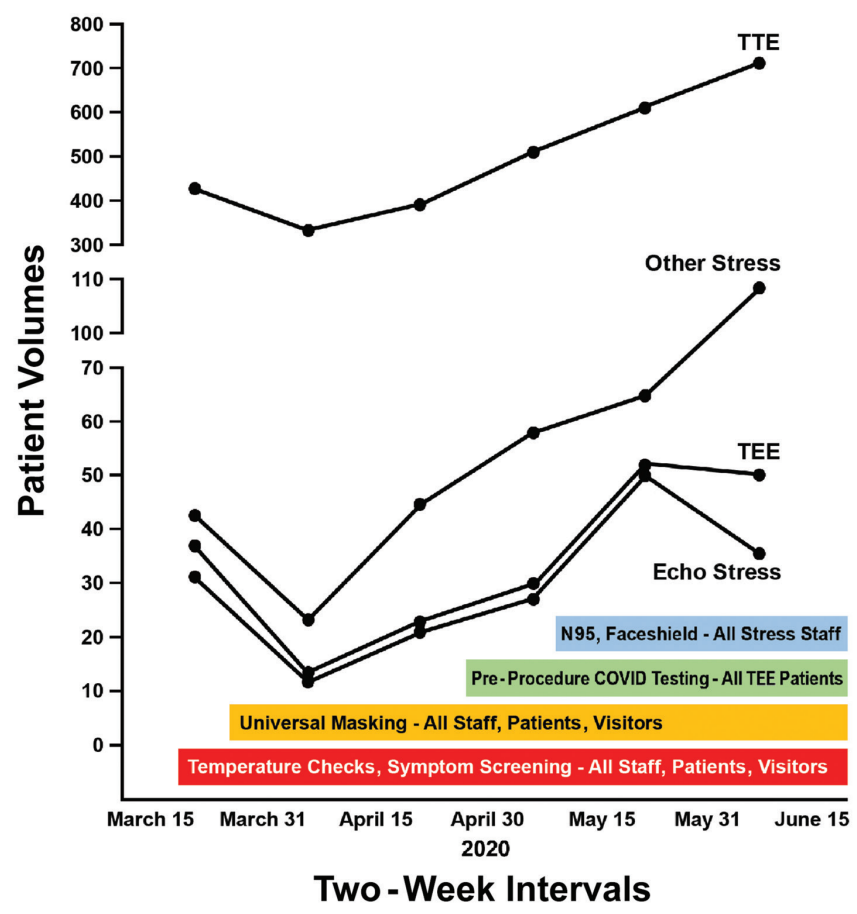

Figure 1. Timeline of modifications and volumes in the echocardiography/stress laboratory over a 3-month period. COVID, coronavirus disease 2019; Echo, echocardiography; TEE, transesophageal echocardiography; TTE, transthoracic echocardiography; Stress, cardiac stress test. 
TEE, with an option of using standard precautions if COVID-19 polymerase chain reaction (PCR) swab was negative. Recognizing the potential for aerosol generation from heavy exercise, we implemented an N95 and face shield requirement for all exercise stress tests, with or without preprocedure COVID-19 testing, in late May 2020.

\section{RESULTS}

Of 50 staff members invited to participate, 43 accepted $(86.0 \%)$. Clinical characteristics of participants are listed in Table 1; the majority were less than 40 years old $(n=30,69.8 \%)$, White $(n=37,86.0 \%)$, and women $(\mathrm{n}=34,79.1 \%)$. Mean body mass index was $24.9 \pm 4.7$ $\mathrm{kg} / \mathrm{m}^{2}$. Clinical roles included cardiac sonographers $(\mathrm{n}=18,41.9 \%)$, nurses $(\mathrm{n}=8,18.6 \%)$, nuclear technicians $(\mathrm{n}=7,16.3 \%)$, physicians $(\mathrm{n}=5,11.6 \%)$, and other team members $(n=5,11.6 \%)$. The 7 invited staff members who did not enroll in the study represented all clinical roles, none more prevalent than the other.

Table 1. Demographics of Echocardiography and Stress Laboratory Staff $(n=43)$

\begin{tabular}{lc}
\hline Variable & $\mathbf{n ~ ( \% )}$ \\
\hline Age & $16(37.2 \%)$ \\
$20-29$ years & $14(32.6 \%)$ \\
$30-39$ years & $5(11.6 \%)$ \\
$40-49$ years & $8(18.6 \%)$ \\
$\geq 50$ years & \\
Race/Ethnicity & $37(86.0 \%)$ \\
White & $4(9.3 \%)$ \\
Asian & $2(4.7 \%)$ \\
Hispanic & \\
Sex & $34(79.1 \%)$ \\
Female & $9(20.9 \%)$ \\
Male & $66.2 \pm 3.7$ \\
Height in inches & $156.8 \pm 32.9$ \\
Weight in pounds & $24.9 \pm 4.7$ \\
Body mass index in kg/m ${ }^{2}$ & $1(2.3 \%)$ \\
Self-reported SARS-CoV-2-positive test & $6(14.0 \%)$ \\
Self-reported respiratory illness since & \\
March 2020 & $2(4.7 \%)$ \\
Loss of taste and/or smell since March 2020 & \\
SARS-CoV-2 IgG antibody test results & $3(7.0 \%)$ \\
Positive & $40(93.0 \%)$ \\
Negative &
\end{tabular}

SARS-CoV-2, severe acute respiratory syndrome coronavirus 2.
Of the 43 participants tested, $3(7.0 \%, 95 \%$ CI: $2 \%-$ $20 \%$ ) had positive SARS-CoV-2 IgG antibody. Of those, 2 staff members had COVID-19 acute illness in the early weeks of the pandemic (ie, fever, cough, loss of taste and smell) but had not been hospitalized: 1 had a subsequent positive SARS-CoV-2 PCR test, and the other was not tested at the time due to a shortage of testing supplies. The third and only other seropositive staff member had no prior symptoms and was surprised at the result. There were 4 additional staff members who reported respiratory symptoms (cough, congestion, fever, myalgia) but who did not develop loss of taste or smell - all 4 tested negative for SARS-CoV-2 IgG antibody.

The 3 participants with seropositivity were all members of the clinical team who had direct and daily patientfacing contact. All 3 engaged in aerosol-generating or potentially aerosol-generating procedures. There was no clear pattern of age, ethnicity, clinical role, body mass index, or sex among these 3 individuals.

\section{DISCUSSION}

We noted $7.0 \%$ seroprevalence of SARS-CoV-2 antibodies among health care personnel who worked fulltime in the echocardiography and stress laboratory and participated in a variety of procedures, some of which were aerosol-generating. ${ }^{14}$ This finding is comparable to other studies in which seroprevalence in health care workers ranged from $1.1 \%$ to $17.1 \% .{ }^{15-19}$ However, our study focused on a small subset of staff members who are regularly involved in aerosol-generating procedures, making it difficult to compare our results with studies of more general health care settings. Although at the time of this writing there is ongoing debate about airborne versus droplet transmission of SARS-CoV-2, ${ }^{20}$ our results may be reassuring to those working in diagnostic imaging. Over a period of 3 months, with exposure to individuals with uncertain COVID-19 status, we did not see a significant prevalence of antibodies to the virus in the staff. In the 3 seropositive staff members, 2 reported being mildly ill (neither hospitalized) and 1 reported no symptoms. As we published previously, none of our unit's core group of cardiac sonographers who perform COVID-19 TTEs on a regular basis were seropositive in that analysis, ${ }^{21}$ confirming that PPE recommendations for TTE in patients with COVID-19 may offer adequate protection. ${ }^{?}$

During the 3-month study time frame prior to participant testing, this clinical unit performed 2973 TTEs (including focused TTEs on patients with COVID-19), 177 stress echocardiograms, 342 other stress tests, and 204 TEEs. This volume was roughly half the volume performed 
during the same time period in the year prior $(4558$ TTEs, 409 stress echocardiograms, 693 other stress tests, and 469 TEEs in 2019). We observed marked reduction in procedure volume from April 1 to April 15, which subsequently increased to $80 \%$ of prepandemic volume by the end of the study period (Figure 1). During this time frame, the COVID-19 patient census steadily rose before decreasing at the end of May. At the height of the initial surge, our hospital was one of the busiest in Wisconsin and had multiple COVID-19-designated floors and intensive care units.

For the first 2 months of this study time frame, Wisconsin was under a statewide stay-at-home order. Much of this study assessed exposure to COVID-19 during this "shutdown;" new challenges may arise as the state continues to re-open and COVID-19 cases increase in local communities. The most consistent safety interventions done by the hospital were the simplest a mask requirement for all people entering the building, social distancing whenever possible, and universal temperature/symptom screening upon entering. ${ }^{11,22}$

\section{Strengths and Limitations}

A strength of this study was near-complete participation by unit staff, making this a truly cross-sectional assessment of seroprevalence in a busy urban hospital laboratory. To our knowledge, this is the first study evaluating seroprevalence in echocardiography and stress laboratories.

There are limitations to this study. First, this study was conducted in a single hospital, and a small number of subjects were included. The small sample size and low prevalence of seropositivity made it impossible to compare differences among demographics. Another study limitation was the lack of staff diversity, as we now know Hispanic and African American populations in the United States are proportionately more likely to get infected with and die from COVID-19. Negative antibody tests do not rule out acute infection but make it less likely that prior infection/exposure had occurred during the 3-month time period. ${ }^{23,24}$ Finally, it is unknown how long antibodies remain in the system, with recent literature showing immune response for 2-3 months or at least 6 months post-SARS-CoV-2 infection, with more research to be done. ${ }^{23,25}$

\section{CONCLUSIONS}

After the first 3 months of the COVID-19 pandemic, a $7.0 \%$ seropositivity rate was observed in echocardiography and stress laboratory staff who regularly participate in aerosol-generating and other procedures. This level suggests the potential benefits of following established society guidelines - universal masking, symptom/temperature screening, and social distancing - which were the predominant interventions implemented by the hospital and clinical unit during the study period. We find our unit's early baseline results reassuring and plan to re-evaluate seroprevalence in laboratory staff after 6 months to assess the prevalence of SARS-CoV-2 antibodies as this pandemic continues.

\section{Patient-Friendly Recap \\ - Concern has been raised about heightened risk of COVID-19 transmission among health care workers who participate in aerosol-generating procedures like cardiac stress testing. \\ - After the first 3 months of the pandemic, study authors found a low prevalence of positive SARS- CoV-2 antibody test results - indicative of past COVID-19 infections - among echocardiography and stress laboratory staff. \\ - Health system interventions such as use of N95/face shields, universal masking, symptom/temperature screening, and social distancing may help prevent disease transmission among health care workers.}

\section{Acknowledgments}

The authors thank the following from Aurora Cardiovascular and Thoracic Services: Jennifer Pfaff and Susan Nord for editorial preparation of the manuscript and Brian Miller and Brian Schurrer for assistance with the figure.

\section{Author Contributions}

Study design: Jain, Khandheria. Data acquisition or analysis: Jain, Kroboth, Ignatowski. Manuscript drafting: Jain, Kroboth, Khandheria. Critical revision: Jain, Khandheria.

\section{Conflicts of Interest}

None.

\section{Funding Sources}

This research was funded in part by Marcus Family Fund for Echocardiography (ECHO) Research and Education (Milwaukee, WI).

\section{References}

1. Deng Q, Hu B, Zhang Y, et al. Suspected myocardial injury in patients with COVID-19: evidence from front-line clinical observation in Wuhan, China. Int J Cardiol. 2020;311:116-21. CrossRef

2. Shi S, Qin M, Shen B, et al. Association of cardiac injury with mortality in hospitalized patients with COVID-19 in Wuhan, China. JAMA Cardiol. 2020;5:802-10. CrossRef

3. Hoehl S, Rabenau H, Berger A, et al. Evidence of SARS$\mathrm{CoV}-2$ infection in returning travelers from Wuhan, China. $N$ Engl J Med. 2020;382:1278-80. $\underline{\text { CrossRef }}$ 
4. World Health Organization. Report of the WHO-China Joint Mission on Coronarvirus Disease 2019 (COVID-19). Published February 28, 2020; accessed November 17, 2020. https://www.who.int/publications/i/item/report-of-the-whochina-joint-mission-on-coronavirus-disease-2019-(covid-19)

5. Mitchell C, Rahko PS, Blauwet LA, et al. Guidelines for performing a comprehensive transthoracic echocardiographic examination in adults: recommendations from the American Society of Echocardiography. $J$ Am Soc Echocardiogr. 2019;32:1-64. CrossRef

6. Gibbons RJ, Balady GJ, Bricker JT, et al. ACC/AHA 2002 guideline update for exercise testing: summary article: a report of the American College of Cardiology/American Heart Association Task Force on Practice Guidelines (Committee to Update the 1997 Exercise Testing Guidelines). Circulation. 2002;106:1883-92. CrossRef

7. Kirkpatrick JN, Mitchell C, Taub C, Kort S, Hung J, Swaminathan M. ASE statement on protection of patients and echocardiography service providers during the 2019 novel coronavirus outbreak: endorsed by the American College of Cardiology. J Am Soc Echocardiogr. 2020;33:648-53. $\underline{\text { CrossRef }}$

8. Papolos A, Narula J, Bavishi C, Chaudhry FA, Sengupta PP. U.S. hospital use of echocardiography: insights from the Nationwide Inpatient Sample. J Am Coll Cardiol. 2016;67:502-11. CrossRef

9. Xian Quah J, Greaves K, Thomas L, Stanton T. The clinical utility and enduring versatility of stress echocardiography. Heart Lung Circ. 2019;28:1376-83. CrossRef

10. ACL Laboratories. Search results: SARS-CoV-2 IgG. Accessed Nov. 26, 2020 https://supplies.acllaboratories.com/ tests-directory/test-data.asp? code $=\mathrm{COV} 2 \mathrm{G}$

11. Hung J, Abraham TP, Cohen MS, et al. ASE statement on the reintroduction of echocardiographic services during the COVID-19 pandemic. J Am Soc Echocardiogr. 2020;33:1034-9. CrossRef

12. Zoghbi WA, DiCarli MF, Blankstein R, et al. Multimodality cardiovascular imaging in the midst of the COVID-19 pandemic: ramping up safely to a new normal. JACC Cardiovasc Imaging. 2020;13:1615-26. CrossRef

13. Capotosto L, Nguyen BL, Ciardi MR, Mastroianni C, Vitarelli A. Heart, COVID-19, and echocardiography. Echocardiography. 2020;37:1454-64. CrossRef
14. Tran K, Cimon K, Severn M, Pessoa-Silva CL, Conly J. Aerosol generating procedures and risk of transmission of acute respiratory infections to healthcare workers: a systematic review. PLoS One. 2012;7(4):e35797. CrossRef

15. Brant-Zawadzki M, Fridman D, Robinson PA, et al. SARS-CoV-2 antibody prevalence in health care workers: preliminary report of a single center study. PLoS One. 2020;15(11):e0240006. CrossRef

16. Chen Y, Tong X, Wang J, et al. High SARS-CoV-2 antibody prevalence among healthcare workers exposed to COVID-19 patients. J Infect. 2020;81:420-6. CrossRef

17. Iversen K, Bundgaard H, Hasselbalch RB, et al. Risk of COVID-19 in health-care workers in Denmark: an observational cohort study. Lancet Infect Dis. 2020;20:1401-8. CrossRef

18. Korth J, Wilde B, Dolff S, et al. SARS-CoV-2-specific antibody detection in healthcare workers in Germany with direct contact to COVID-19 patients. J Clin Virol. 2020;128:104437. CrossRef

19. Moscola J, Sembajwe G, Jarrett M, et al. Prevalence of SARSCoV-2 antibodies in health care personnel in the New York City area. JAMA. 2020;324:893-5. CrossRef

20. Klompas M, Baker MA, Rhee C. Airborne transmission of SARS-CoV-2: theoretical considerations and available evidence. JAMA. 2020;324:441-2. CrossRef

21. Ignatowski D, Zemke S, Payne A, Khandheria BK. Striking the balance between safety of patients and team members with effective, high-quality care. J Am Soc Echocardiogr. 2020;33:1421. CrossRef

22. Klompas M, Morris CA, Sinclair J, Pearson M, Shenoy ES. Universal masking in hospitals in the COVID-19 era. $N$ Engl $J$ Med. 2020;382:e63. CrossRef

23. Long QX, Tang XJ, Shi QL, et al. Clinical and immunological assessment of asymptomatic SARS-CoV-2 infections. Nat Med. 2020;26:1200-4. CrossRef

24. Xiang F, Wang X, He X, et al. Antibody detection and dynamic characteristics in patients with coronavirus disease 2019. Clin Infect Dis. 2020;71:1930-4. CrossRef

25. Figueiredo-Campos P, Blankenhaus B, Mota C, et al. Seroprevalence of anti-SARS-CoV-2 antibodies in COVID-19 patients and healthy volunteers up to 6 months post disease onset. Eur J Immunol. 2020;50:2025-40. CrossRef

(C) 2021 Advocate Aurora Health, Inc. 